\title{
Bioconversion of Penicillin to Cephalosporin
}

\author{
Rahul Jaiswal, Dipak Vora \\ Department of Microbiology, Ramnarain Ruia College, Matunga, Mumbai - 400019.
}

\begin{abstract}
Cephalosporins are known as $3^{\text {rd }}$ generation broad spectrum Beta lactam antibiotics, which can also be produced synthetically. Commonly, chemical ring expansion followed by an enzymatic removal of the phenylacetyl side chain is commonly employed to convert penicillin $G$ into 7-aminodeacetoxycephalosporanic acid, the precursor for the manufacture of semisynthetic cephalosporins. This process requires several steps, is expensive and highly polluting. Thus there is a need to device a simple biological route to replace the chemical process. A mutant of Streptomyces clavuligerus NP1 was reported to converts Penicillin $G$ to Deacetoxycephalosporin $G$ (DAOG;phenylacetyl-7-aminodeacetoxycephalosporanic acid) enzymatically ${ }^{[5,8]}$. This enzyme, deacetoxycephalosporin synthase has the potential for the large scale transformation of Penicillin $G$ to deacetoxycephalosporin. The present work studies the conditions required for efficient transformation of Penicillin G to Deacetoxycephalosporin using the wild type strain Streptomyces clavuligerus . Detection of cephalosporin was carried out using various methods. Additionally succinic acid formation was also studied as it could be used as a commercially important by product of the transformation. Deacetoxycephalosporin synthase also extracted and partially purified and characterised.
\end{abstract}

Keywords: Deacetoxycephalosporin synthase, Benzylpenicillin, Cephalosporin.

Accepted Date: 23 Mar 2013

\section{Introduction}

For the past few decades, cephalosporins have been widely used as antimicrobial therapeutic agents owing to their broad activity spectra and low toxicity. A large percentage of cephalosporins is derived from 7 aminodeacetoxycephalosporanic acid (7-ADCA) by the addition of different side chains to give various semisynthetic cephalosporins with different antimicrobial spectra and pharmacokinetics ${ }^{[1,7]}$ Cephalosporins are $\beta$-lactam antibiotic agents widely used for the clinical treatment of bacterial infection. Biosynthesis of cephalosporin in Streptomyces clavuligerus proceeds through a biosynthetic pathway that includes expansion of the five-membered thiazolidine ring of the intermediate penicillin $\mathrm{G}$ into the six-membered dihydrothiazine ring of deacetoxycephalosporin C (DAOC). A very valuable step in the economical production of semisynthetic cephalosporin antibiotics. Studies have been carried out to transform Penicillin G to Deacetoxycephalosporin using a mutant strain of Streptomyces clavuligerus NP1and the detection was carried out ${ }^{[1,2,5]}$. The present work studies the conversion of Penicillin G to Deacetoxycephalosporin C using wild type strain Streptomyces clavuligerus( Resting cells \& Cell extracts ). Reaction mixtures was prepared studying the conditions required for optimum ring expansion, a standard reaction mixture was prepared according to the conditions required for transformation using a mutant strain. Detection of cephalosporin was done by several methods, the methods described are simple and sensitive, thus making detection an inexpensive protocol ${ }^{[14]}$. By, chemical process it is found out that the byproducts released are highly polluting, biochemical process takes care of this. Succinic acid is one of the byproducts released during the biotransformation process is detected.

The enzyme Deacetoxycephalosporin synthase was extracted and partially purified by ammonium sulphate precipitation. Detection of the enzyme was done using SDS-PAGE ${ }^{[10}$

\section{Materials \& Methods ${ }^{[1,4,12,13]}$}

Microorganism

Streptomyces clavuligerus. Streptomyces clavuligerus MTCC 1142 was first described by Higgens and Kastner, who isolated it from a South American soil sample was obtained from MTCC( Microbial Type Culture Collection and Gene Bank) IMTECH Chandigarh.

Media and Culture Conditions

Media constituents (100 ml)

Glucose : $0.4 \mathrm{~g}$,Yeast extract : $0.4 \mathrm{~g}$, Malt extract : $1 \mathrm{~g}$, Distilled water : $100 \mathrm{ml}$

Autoclaved at $15 \mathrm{psi}$ for $20 \mathrm{mins}$, and later inoculated with $40 \mu \mathrm{l}$ of culture suspension (prepared in 50\% glycerol and stored at $-20^{\circ} \mathrm{C}$ ) incubated on a rotary shaker at RT for $24 \mathrm{hrs}$. 
Preparation of Cell-Free Extracts

Fermentation broths were centrifuged at $8,000 \times g$ and $4^{\circ} \mathrm{C}$ for $10 \mathrm{~min}$. Pellets were washed twice by using 50 $\mathrm{mM}$ Tris $\cdot \mathrm{HCl}$ supplemented with $0.1 \mathrm{mM}$ DTT. The cells were resuspended in the same buffer and were disrupted by $1 \mathrm{~min}$ sonication treatment at $4^{\circ} \mathrm{C}$. This lysate was centrifuged at $14,000 \times \mathrm{g}$, for $20 \mathrm{~min},\left(4^{\circ} \mathrm{C}\right)$ to remove cell debris.

\section{Preparation of Resting Cells}

$40 \mu \mathrm{l}$ of culture suspension ( prepared in $50 \%$ glycerol and stored at $-20^{\circ} \mathrm{c}$ ) kept in shaker conditions at RT for $24 \mathrm{hrs}$ in the same media discussed above. Cells were grownas described above. Pellets were washed twice with distilled water and, finally were resuspended in $10 \mathrm{ml}$ of distilled water. $1 \mathrm{ml}$ of this cell suspension were used in the reaction mixture.

Standard Reaction mixture consisted of $\mathrm{FeSO}_{4} 1.8 \mathrm{mM}, \mathrm{MgSO} 48 \mathrm{mM}, \mathrm{KCl} 8 \mathrm{mM}$, Tris $\mathrm{HCl} 50 \mathrm{mM}$ pH 7.4 .Autocalved at 15 psi for 20 mins and later alpha - keto glutarate and DTT ( dithiotreitol) by filter sterilization Alpha - keto glutarate $1.28 \mathrm{mM}$, DTT $14 \mathrm{mM} \&$ Penicillin G 2mg/ml, Distilled water $100.0 \mathrm{ml}$.

\section{Ring Expansion Reaction}

$1 \mathrm{ml}$ of cell extract was added in $5 \mathrm{ml}$ of reaction mixture and same for resting cells. Reaction mixtures were incubated in test tubes (cell-free extract resting cells) on a rotary shaker at RT. Reactions containing the protein extract were stopped at various times by mixing $0.5 \mathrm{ml}$ of reaction mixture with $0.5 \mathrm{ml}$ of methanol. In the case of resting cells, samples were centrifuged to remove cells, and supernatants were transferred to new tubes. Expandase activity was detected by bioassay plate technique. Luria-Bertani medium (1\% tryptone/0.5\% $\mathrm{NaCl} / 0.5 \%$ yeast extract $/ 0.1 \%$ glucose) and $0.8 \%$ agar medium seeded with Escherichia coli . holes were bored on the plates and 50 microlitre was inoculated in the holes ,the plates were incubated overnight at $37^{\circ} \mathrm{C}$. The reaction mixture samples were further assayed below.

\section{Detection of Cephalosporin \& Bioautography}

$5 \mu \mathrm{l}$ amounts of ring expansion reaction mixtures samples ( cell extracts \& resting cells )were spotted onto a cellulose thin-layer chromatography sheet( Whattman filter paper). The chromatogram was developed in n-butanol-acetic acid-water (3:1:1), dried thoroughly, and then placed face-down on an agar slab inoculated with Escherichia coli and was incubated overnight at $37^{\circ} \mathrm{C}$, after removing the cellulose sheet the agar slab was then flooded with $5 \%$ trichloroacetic acid to improve visualization of the inhibition zones.

\section{Detection of Succinic acid:}

$5 \mu \mathrm{l}$ amounts of ring expansion reaction mixtures samples ( cell extracts \& resting cells) were spotted onto a Silica gel 60 F254 plates. Standard, Pure Succinic acid obtained from MOLYCHEM was used. The chromatogram was developed in ethanol: ammonium solution : water ( $20: 5: 3$ ). Dried thoroughly and observed under U.V illuminator at $254 \mathrm{~nm}$.

\section{Direct Spectrophotometric Assay}

$1 \mathrm{ml}$ of the ring expansion reaction mixture samples (either cell extracts \& resting cells ) were placed in non reflecting quartz cuvettes.. Reactions were monitored at $260 \mathrm{~nm}$. Standard used was Cefotaxime sodium( Cefotax*).

\section{Ammonium sulphate precipitation \& SDS-PAGE}

Ammonium sulphate precipitation was carried out using the standard protocol. Dialysis of the precipitated sample was carried out and after dialysis the concentrated protein samples was electrophorised using SDSPAGE.

\section{Results :}

1) Detection of conversion of Penicillin to Cephalosporin in:-

Fig 1a) Cell extract: 
Fig 1b) Resting cells:
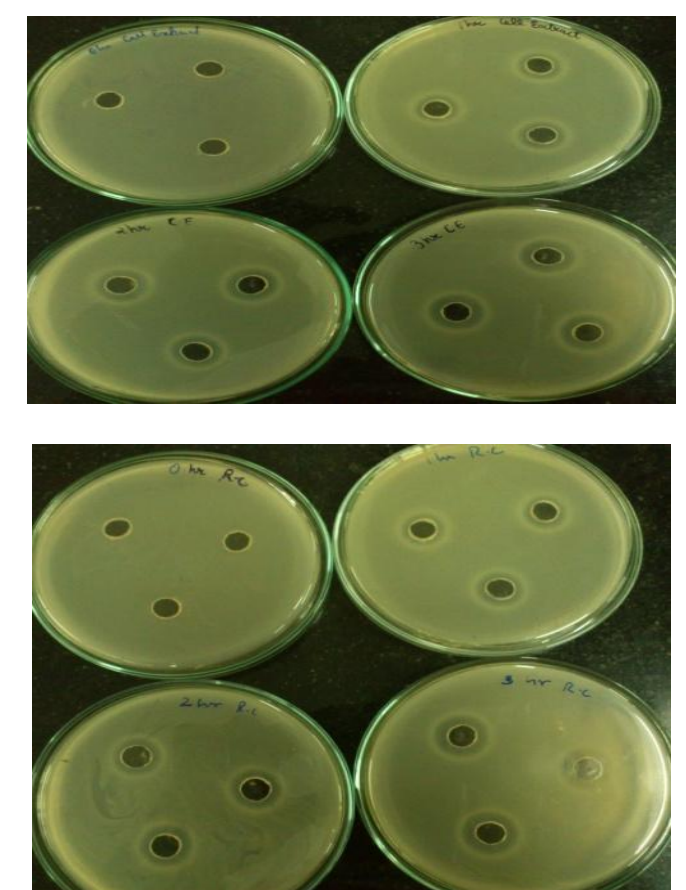

Plates from top left: $0 \mathrm{hr}$ sample, top right : $1 \mathrm{hr}$ sample Bottom left : $2 \mathrm{hr}$ sample, bottom right : $3 \mathrm{hr}$ sample

Graphs obtained by measuring the zone of inhibition:

Graph was plotted with respect to time the increase in the zone of inhibition, interpreting that as time increases there is an increase in the inactivation of penicillin using Cell Extract.

Fig 1c) Cell extracts graph according to zone of inhibition: $x$ axis $=$ no. of hours ; $y$ axis $=$ zone size $(\mathrm{mm})$

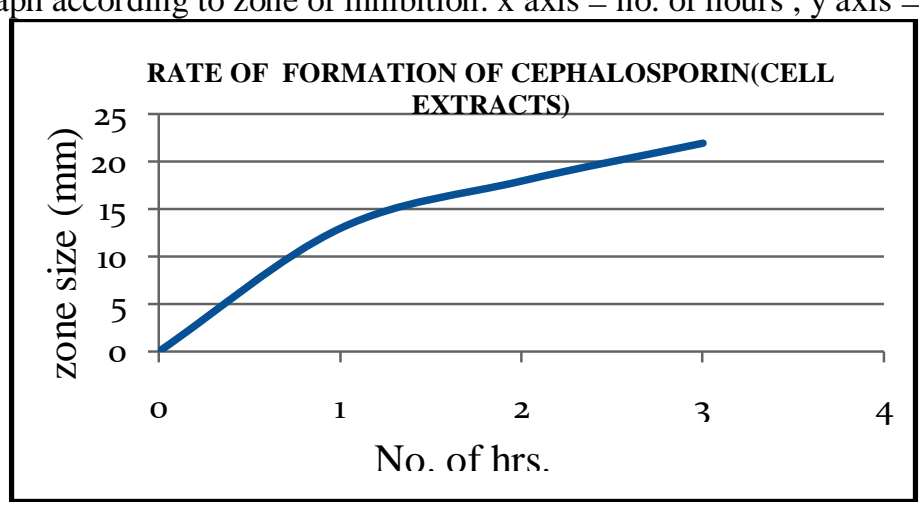

Graph was plotted with respect to time the increase in the zone of inhibition, interpreting that as time increases there is an increase in the inactivation of penicillin using Resting Cells.

Fig 1d) Resting cells graph according to the zone size: $x$ axis $=$ no. of hours , y axis $=$ zone size $(\mathrm{mm})$

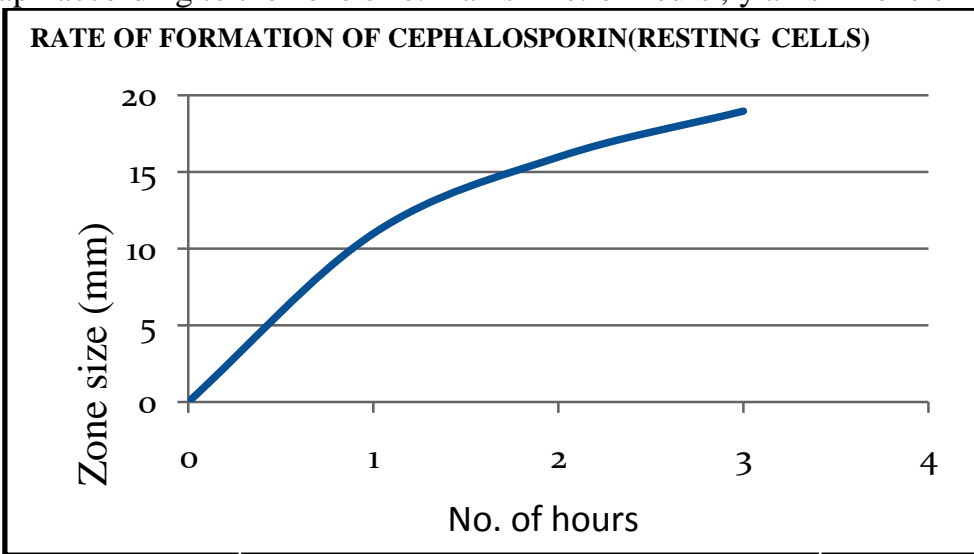




\section{2) Bioautographic detection of cephalosporin}

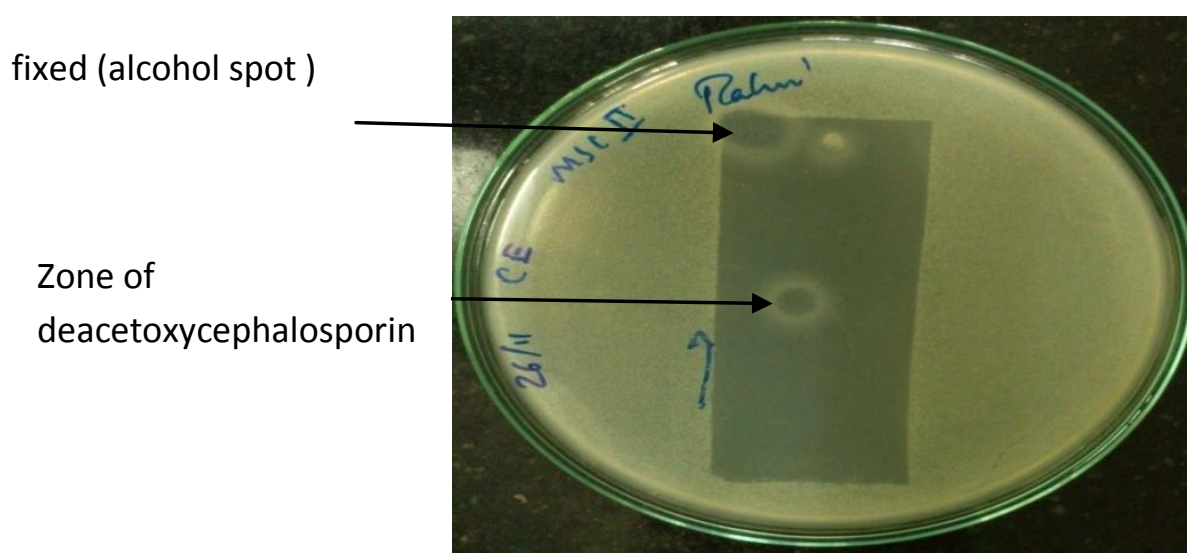

Fig 2) A sample spotted with a cell extract reaction sample showed the zone spot of deacetoxycephalosporin. Bioautograph is one of the various methods used, the chromatogram which was developed using the Mobile phase : n-butanol: acetic acid: water $3: 1: 1)$ and was then completely air dried and placed on LB plate seeded with E.coli and incubated at RT for 24 hours.

3) Succinic acid detection using Thin layer chromatography

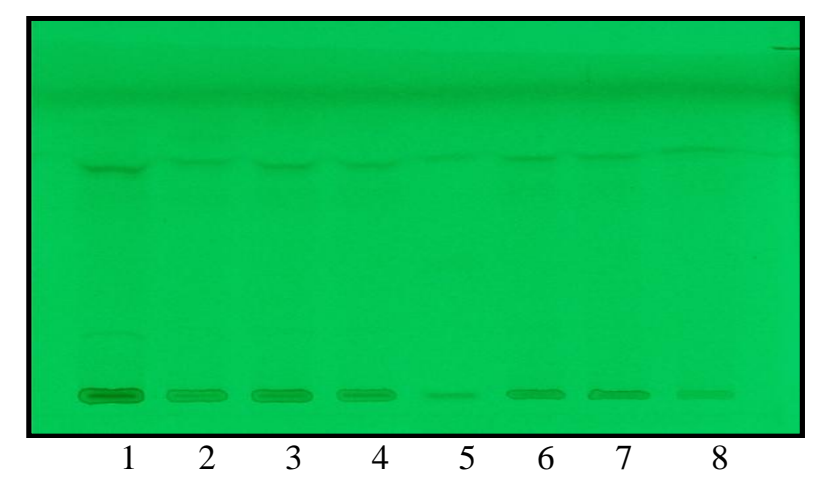

Fig 3 ) Detection of succinic acid using TLC

Spotting order: Track 1,2: Resting cells 4hr; Track 3: Cell extract 4hr; Track 5: Succinic acid(standard); Track 6: Cell Extract 2hr; Track 7,8: Cell Extract 3hr

$254 \mathrm{~nm}$ without derivatization

Abbre : RC= Resting cell, $\mathrm{CE}=$ Cell extract

The RF obtained showed the presence of succinic acid when compared to the RF of Standard used i.e. Pure succinic acid obtained from MOLYCHEM .

4) Quantitation of cephalosporin by Spectrophotometric assay

With respect to the property of the dihydrothiozine moiety of cephalosporin which has the ability to absorb UV light at $260 \mathrm{~nm}$. The reaction mixture samples was assayed spectrophotometrically to determine the presence of cephalosporin.

Graph was plotted with respect to time the increase in the absorbance, there was increase in the absorbance obtained while using Cefotaxime Sodium (Cefotax) as a standard for Spectrophotometric assay 
Scale : For Standard: $\mathrm{X}$-axis= units of cefatoxime sodium $500 \& \mathrm{Y}$ axis $=$ OD at $260 \mathrm{~nm}$

Fig 4a) ) Standard Cefotaxime sodium

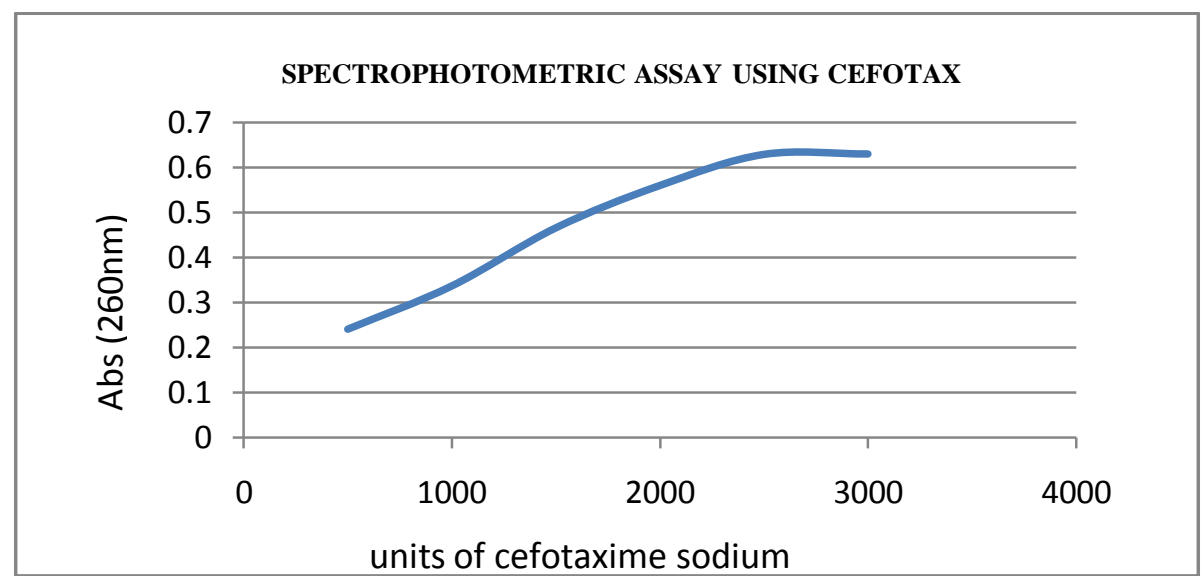

Graph was plotted with respect to time the increase in the absorbance, there was increase in the absorbance obtained while using Cell Extracts for Spectrophotometric assay.

Fig 4b) Cell extracts:

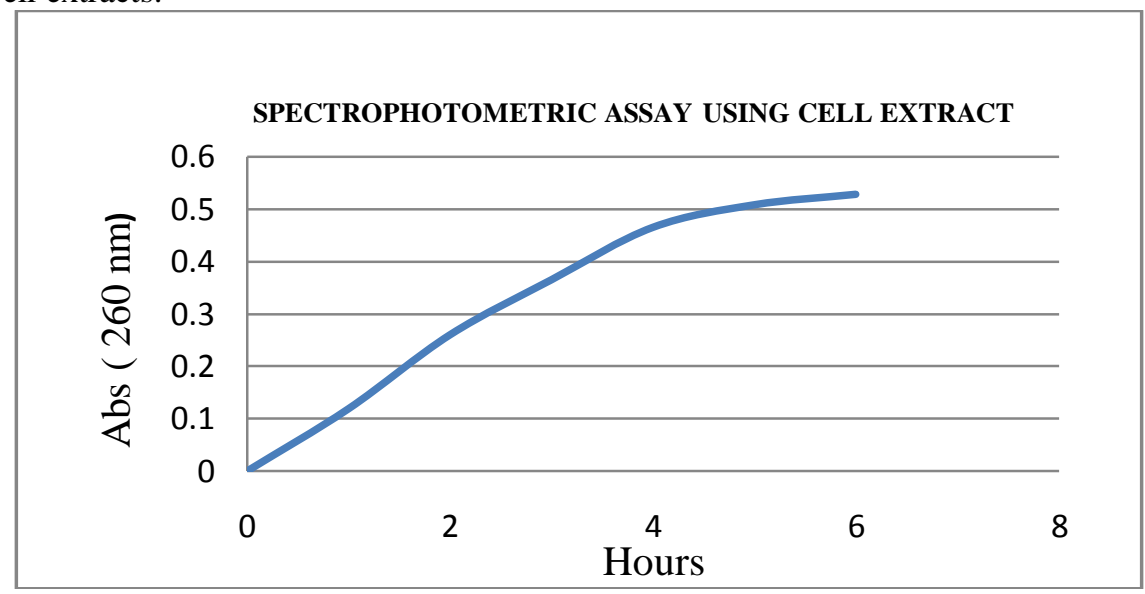

Scale : For Cell extract \& Resting cell: $\mathrm{X}$ axis= No. of hours \& Y axis $=$ OD at $260 \mathrm{~nm}$

Graph was plotted with respect to time the increase in the absorbance, there was increase in the absorbance obtained while using Resting Cells for Spectrophotometric assay

Fig 4c : Resting cells:

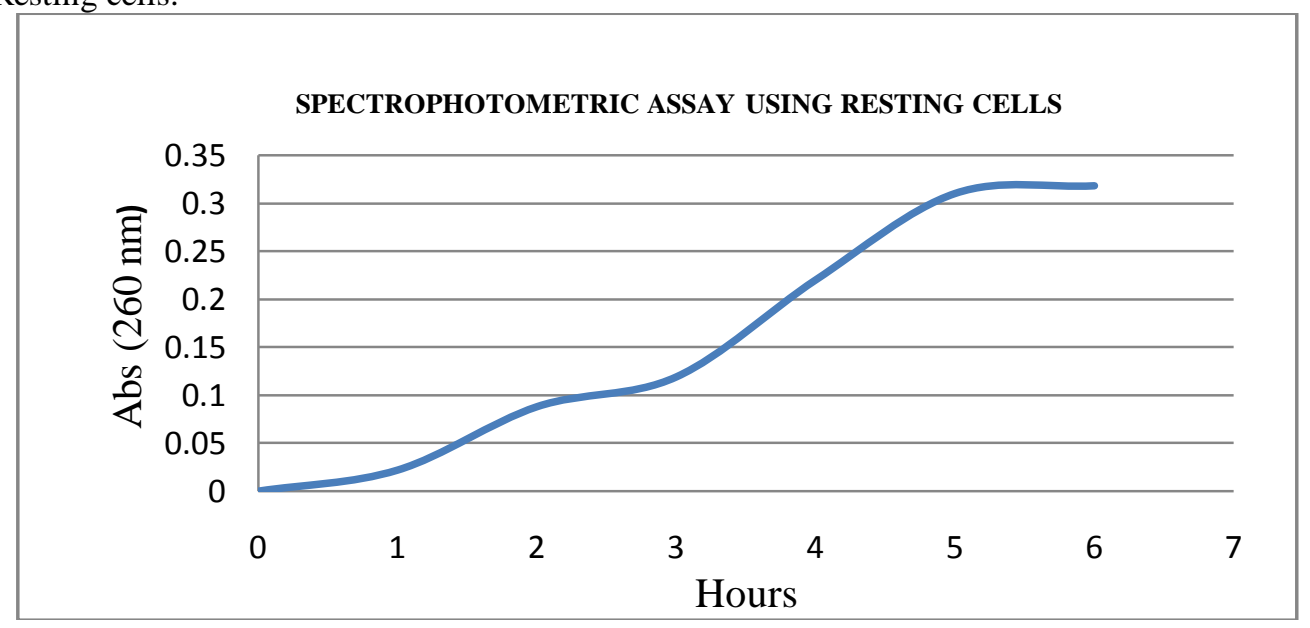


5) $S D S-P A G E$

SDS-PAGE was carried out to detect the presence of Deacetoxycephalosprin synthase which is an enzyme responsible to bring about the conversion. The molecular weight of the enzyme was earlier reported to be around $41 \mathrm{Kda}$. A standard protein DNA ladder in the range of $240 \mathrm{kda}-5 \mathrm{kda}$ is used.

Fig 5) Electrophorised Gel of the dialysed protein samples.

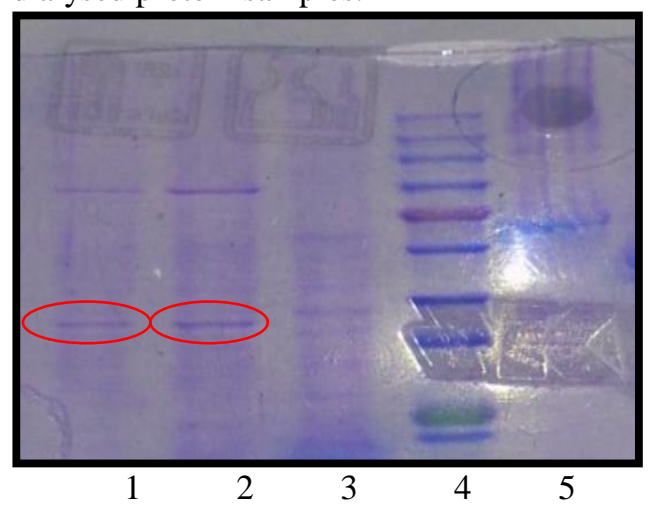

Lane 1: dailysis sample 1; Lane 2: dailysis sample 2 ; Lane 3: dialysis sample 3 ;Lane 4: protein ladder ; Lane 6 : Bovine albumin

RESULT : Lane 1 and Lane 2 showed presence of $41 \mathrm{kda}$ protein which is approximate mol. Wt of DAOCS

5) Ammonium sulphate Protein purification :

\section{Activity of deacetoxycephalosporin on purification remains unstable}

\section{Discussion}

Deacetoxycephalosporin is one of the major intermediates required for synthesis of cephalosporins. The physicochemical conditions required for enhanced production of deacetoxycephalosporin was established using both resting cells \& cell extracts of wild type strain Streptomyces clavuligerus . Higher yields were obtained as compared to that reported in the literature. Further, the byproducts obtained consequent to this transformation also were of commercial value. ${ }^{[15-19]}$.

The qualitative formation of Cephalosporin was determined both by TLC and bioautography. The product formed was quantitated spectrophotometrically using Sodium cefotaxime (Cefotax) as a standard reference. Before this study, Penicillin G was found to be inactive as a substrate for Deacetoxycephalosporin synthase (EC.1.14.20.1) present in Streptomyces clavuligerus (resting cells and cell-free extracts) under the conditions optimal for ring expansion of penicillin $G$ demonstrated the transformation of Penicillin $G$ to Cephalosporin with an increase in the concentration of the substrate, co-substrate and the cofactors.

Deacetoxycephalosporin synthase enzyme which is mainly responsible for this transformation was extracted and partially purified. The protein extraction and purification was carried out using ammonium sulphate precipitation and dialysis .

Added advantage of the biotransformation is the production of a commercially important environment friendly by product, Succinic acid. Succinic acid is one of the major byproduct produced when deacetoxycephalosporin synthase catalyses the reaction containing Penicillin $\mathrm{G}$ and oxy-keto glutarate (reaction mixture) $[12,14]$.

\section{References}

[1]. Adrio, J. L., J. Velasco, G. Soler, M. Rodriguez Saiz, J. L. Barredo, and M. A. Moreno. 2001. Extracellular production of biologically active deacetoxycephalosporin C synthase from Streptomyces. Biotechnol. Bioeng. 75:485-491.

[2]. Baez-Vasquez, M. A., J. L. Adrio, J. M. Piret, and A. L. Demain. 1999. Further studies on the bioconversion of penicillin G into deacetoxycephalosporin G by resting cells of Streptomyces clavuligerus NP-1. Appl. Biochem. Biotechnol. 81:145-152.

[3]. Baker, B. J., J. E. Dotzlaf, and W. K. Yeh. 1991. Deacetoxycephalosporin C hydroxylase ofStreptomyces clavuligerus. Purification, characterization, bifunctionality, and evolutionary implication. J. Biol. Chem. 266:5087-5093.

[4]. Chia-Li, Yunn-Bor Yang, Wen-Ching Wang, Wen-Chi Liu,*Engineering Streptomyces clavuligerus Deacetoxycephalosporin C Synthase for Optimal Ring Expansion Activity toward Penicillin G, Appl Environ Microbiol. 2003 April; 69(4): 2306-2312.

[5]. Demain, A. L., and M. A. Baez-Vasquez. 2000. Immobilized Streptomyces clavuligerus NP1 cells for biotransformation of penicillin G into deacetoxycephalosporin G. Appl. Biochem. Biotechnol. 87:135-140.

[6]. Dotzlaf, J. E., and W.-K. Yeh. 1987. Copurification and characterization of deacetoxycephalosporin C synthetase/hydroxylase from Cephalosporium acremonium Cephalosporium acremonium. J. Bacteriol.169:1611-1618. 
[7]. Felix, H. R.; H. H. Peter \& H. J. Treichler: Microbiological ring expansion of penicillin N. J. Antibiotics 34: 567-575, 1981

[8]. Hiroshi cho, Adrio J L , Luengo M J, Piret J M, Demain A L. Elucidation of conditions allowing conversion of penicillin G and other penicillins to deacetoxycephalosporins by resting cells and extracts of Streptomyces clavuligerus NP1, PNAS, vol. 95 no. 20 , 11544-11548

[9]. Hook D. J.; L. T. Chang, R. P. Elander \& R. B. Morin: Stimulation of the conversion of penicillin N to cephalosporin by ascorbic acid, a-ketoglutarate, and ferrous ions in cell-free extracts of strains of Cephalosporium acremonium. Biochem. Biophys. Res. Commun. 87: 258-265,1979

[10]. Hook, D. J.; R. P. Elander \& R. B. Morin: Recent developments with cell-free extracts on the enzymic biosynthesis of penicillins and cephalosporins. In "Symposium on Enzyme Biosynthesis of Peptides", Ed., H. KLEINKAUF, in press, 1981

[11]. J E. Baldwin and M. James C. Crabbe, A spectrophotometric assay for deacetoxycephalosporin C synthase, The Dyson Perrins Laboratory, University of Oxford, South Parks Road, Oxford OX1 3Q Y, England, Volume 214, number 2, 357-361 1987

[12]. Jensen S E, Demain A L. In: Biochemistry and Genetics of Antibiotics Biosynthesis. Vining L C, Stuttard C, editors. Boston: Butterworth-Heinemann; 1993. pp. 239-268.

[13]. Jensen SE, Westlake DW, Bowers RJ, Wolfe S. Cephalosporin formation by cell-free extracts from Streptomyces clavuligerus. $J$ Antibiot (Tokyo). 1982 Oct;35(10):1351-60

[14]. Lee, H. J., M. D. Lloyd, K. Harlos, I. J. Clifton, J. E. Baldwin, and C. J. Schofield. 2001. Kinetic and crystallographic studies on deacetoxycephalosporin C synthase (DAOCS). J. Mol. Biol. 308:937-948.

[15]. Maeda K, Luengo J M, Ferrero O, Wolfe S, Lebedev M Y, Fang A, Demain A L. Enzyme Microb Technol.1995;17:231-234.

[16]. Sawada Y.; N. A. Hunt \& A. L. Demain: Further studies on microbiological ring-expansion of penicillin N. J. Antibiotics 32:1303-1310,1979

[17]. Sawada Y.; N. A. Solomom \& A. L. Demain: Stimulation of cell-free ring expansion of penicillin N by sonication and Triton X-100. Biotechnol. Lett. 2: 43- 48, 1980

[18]. Sim, J., and T.-S. Sim. 2001. In vitro conversion of penicillin G and ampicillin by recombinantStreptomyces clavuligerus NRRL 3585 deacetoxycephalosporin C synthase.Enzyme Microbiol. Technol. 29:240-245.

[19]. Velasco, J., J. L. Adrio, M. A. Moreno, B. Diez, G. Soler, and J. L. Barredo. 2000. Environmentally safe production of 7aminodeacetoxycephalosporanic acid (7-ADCA) using recombinant strains of Acremonium. Nat. Biotechnol. 18:857-861

[20]. Yoshida, M.; T. Konomi, M. Kohsaka, J. E. Baldwin, S. Herchen, P. Singh, N. A. Hunt \& A. L. Demain: Cell-free ring expansion of penicillin $\mathrm{N}$ to deacetoxycephalosporin C by Cephalosporium acremonium CW-19 and its mutants. Proc. Natl. Acad. Sci. U.S.A. 75: 6253-6257,1978 